\title{
As Razões do Opt-out: um Estudo sobre Mulheres que Interromperam suas Carreiras em Função da Maternidade
}

\section{Why Opt-out? A Study About Women Who Interrupted Their Careers to Become Full Time Mothers}

\author{
Paula Furtado Hartmann de Queiroz Monteiro \\ Doutoranda em Administração. Programa de Pós-Graduação em Administração da Pontifícia \\ Universidade Católica do Rio de Janeiro (IAG/PUC-Rio) \\ Rua Marquês de São Vicente, 225 - Prédio IAG - Gávea - Rio de Janeiro, RJ. \\ CEP: 22451-900 \\ E-mail: paulafhartmann@gmail.com
}

\author{
Ana Heloísa da Costa Lemos \\ Doutora em Administração - IAG - PUC Rio. \\ Professora Adjunta do Departamento de Administração da Pontifícia Universidade Católica \\ do Rio de Janeiro (IAG/PUC-Rio). \\ Rua Marquês de São Vicente, 225 - Prédio IAG - Gávea - Rio de Janeiro - RJ. \\ CEP: 22451-900 \\ E-mail: aheloisa@iag.puc-rio.br
}

\begin{abstract}
Alessandra de Sá Mello da Costa
Doutora em Administração pela EBAPE/FGV. Professora Adjunta do Departamento de Administração da Pontifícia Universidade Católica do Rio de Janeiro (IAG/PUC-Rio). Rua Marquês de São Vicente, 225 - Prédio IAG - Gávea - Rio de Janeiro - RJ.

CEP: 22451-900

E-mail: alessandra.costa@iag.puc-rio.br
\end{abstract}

Resumo: Este artigo teve como objetivo compreender as experiências das mulheres que aderiram ao movimento opt-out. Para alcançar esse objetivo, buscou-se respostas para as seguintes perguntas: Quais foram os motivos que levaram mulheres com carreiras consolidadas a aderirem ao movimento opt-out? Como foi a vivência dessas mulheres durante o tempo em que ficaram em casa? A metodologia adotada foi de natureza qualitativa. Para coleta dos dados foram realizadas quatorze entrevistas semiestruturadas (gravadas e transcritas) com mulheres com formação superior e pós-graduação, residentes nas cidades do Rio de Janeiro e São Paulo, e que atuaram em ambientes organizacionais de segmentos diferentes do mercado privado. Para análise do material coletado em campo, foi utilizado o método análise de conteúdo qualitativa, a partir de quatro categorias de análise:(1) os obstáculos do mundo do trabalho; (2) o exercício da maternidade; (3) a ausência paterna; e (4) os desafios da maternidade em período integral. Os resultados revelaram que as entrevistadas não se afastaram de suas carreiras apenas devido a um desejo de se dedicar unicamente aos filhos, mas por razões mais complexas que compreendem, também, aspectos relacionados à dinâmica do trabalho, aos filhos e aos companheiros, tais como: longas jornadas de trabalho, estigma contra as mães no local de trabalho, problemas de saúde dos filhos e ausência dos companheiros no cuidado das crianças e nas tarefas domésticas. Além disso, constatou-se que, durante o tempo de afastamento, elas vivenciaram experiências que envolvem tanto sentimentos positivos, como acompanhamento do desenvolvimento dos filhos, quanto negativos, como crises de identidade, sentimento de improdutividade e medo do futuro. Tais resultados conduziram a uma leitura crítica do movimento opt-out, por se entender que tal fenômeno contribui para a manutenção do status $q u o$ frente às desigualdades estruturais e organizacionais. 
Palavras-chaves: Opt-Out; Interrupção de Carreira; Mulher; Carreira.

Abstract: This article aimed to understand the experiences of women who joined the opt-out movement. To achieve this goal, answers were sought to the following questions: What were the reasons that led women with consolidated careers to join the opt-out movement? How was the experience of these women during the time they were at home? The methodology adopted was of a qualitative nature. For data collection, fourteen semi-structured interviews (recorded and transcribed) were carried out with women with higher education and postgraduate studies, residing in the cities of Rio de Janeiro and São Paulo, and who worked in organizational environments from different segments of the private market. To analyze the material collected in the field, the qualitative content analysis method was used, based on four categories of analysis: (1) obstacles in the world of work; (2) the exercise of motherhood; (3) paternal absence; and (4) the challenges of full-time motherhood. The results revealed that the interviewees did not leave their careers only due to a desire to dedicate themselves solely to their children, but for more complex reasons that also include aspects related to the dynamics of work, children and partners, such as: long working hours, stigma against mothers in the workplace, children's health problems and the absence of companions in childcare and household chores. In addition, it was found that, during the time away, they experienced experiences that involve both positive feelings, such as monitoring the development of their children, and negative ones, such as identity crises, feelings of unproductiveness and fear of the future. Such results led to a critical reading of the opt-out movement, as it is understood that this phenomenon contributes to the maintenance of the status quo in the face of structural and organizational inequalities.

Keywords: Opt-Out; Career Interruption; Woman; Career.

\section{INTRODUÇÃO}

O termo opt-out - lançado por Lisa Belkin em 2003, no artigo “The Opt-Out Revolution”, publicado no The New York Times Magazine - tornou-se comum no vernáculo relacionado aos estudos de carreira e gênero, ao sinalizar o êxodo de mulheres altamente qualificadas do mercado de trabalho para se dedicarem com exclusividade aos filhos (MAINIERO; SULLIVAN, 2006). Tal fenômeno, ancorado em uma cultura neoliberal (LEWIS; BENSCHOP; SIMPSON, 2017), reflete, sobretudo, um movimento de mulheres heterossexuais, brancas, casadas e de classe média, associando-o a um privilégio de classe e raça (AKASS, 2012). As descrições do fenômeno opt-out sugerem que as mulheres aderentes ao movimento podem pagar por sua liberdade de escolha, viver sobre seus próprios termos e criar suas próprias definições de sucesso (BIESE, 2017).

O rótulo "opt-out revolution" ganhou proeminência e novas pesquisas surgiram, na tentativa de compreendê-lo (VAVRUS, 2007; STONE, 2007; KUPERBERG; STONE, 2008; MAINIERO; SULLIVAN, 2006; BIESE, 2017; STONE; LOVEJOY, 2019). Estudos acerca das causas que levaram ao movimento opt-out demonstraram que, além do desejo de se dedicar unicamente aos filhos, outros fatores também afetaram a decisão das mulheres de deixar suas carreiras, tais como: falta de reconhecimento e desafio profissional; discriminação de gênero no ambiente organizacional; busca por autenticidade; difícil relação entre trabalho e família; e ausência da participação do companheiro no cumprimento das atividades domésticas e de cuidado dos filhos (MAINIERO; SULLIVAN; 2006; STONE, 2007; STONE; LOVEJOY, 2019).

Ao mesmo tempo em que o fenômeno opt-out foi largamente divulgado, ele também foi muito criticado. Alguns pesquisadores levantaram questionamentos, sobretudo, acerca da noção de "opção" que aparece na narrativa do movimento. Estes estudiosos argumentam que o papel tradicionalmente atribuído às mulheres de criação dos filhos, somado à atuação em um ambiente 
de trabalho inflexível e exigente, conduziu as mulheres a tomarem decisões que não são retratadas de forma adequada no discurso que enfatiza a questão da escolha (STONE, 2007; GREGORY; MILNER, 2009). Tais narrativas concluem que qualquer desequilíbrio de gênero nos locais de trabalho ou na sociedade em geral é diretamente atribuível às escolhas das mulheres (VAVRUS, 2007).

A dificuldade em conciliar as demandas do trabalho com as da maternidade é um fator determinante para a interrupção de carreira de muitas mulheres (MAINIERO; SULLIVAN, 2006). Em novembro de 2019, a revista Exame publicou uma pesquisa realizada pela Mãe Corporate e o Movimento Mulher 360, com quatro mil mulheres de treze grandes empresas brasileiras, que apontou que, oito em cada dez, já pensaram em deixar o seu trabalho após a maternidade. Dentre essas, $87 \%$ relataram que a situação financeira é uma razão importante para a sua permanência no emprego (FILIPPE, 2019).

Diante do exposto, este artigo buscou respostas para as seguintes perguntas: Quais foram os motivos que levaram mulheres com carreiras consolidadas a aderirem ao movimento optout? Como foi a vivência dessas mulheres durante o tempo em que ficaram em casa? Portanto, buscou-se compreender as experiências das mulheres que aderiram ao movimento opt-out. Para alcançar esse propósito, optou-se por uma pesquisa de natureza qualitativa, que envolveu o recolhimento de depoimentos de profissionais que interromperam as suas carreiras para se dedicarem à maternidade em período integral.

A presente pesquisa é relevante para: (i) os estudos de carreiras e gênero, ao ampliar o conhecimento já produzido sobre o processo vivenciado pelas mulheres que aderem ao fenômeno opt-out; (ii) as organizações, ao gerar reflexões acerca das dificuldades encontradas por essas mulheres de conciliar as diferentes demandas de suas vidas, após a chegada dos filhos;.e (iii) a sociedade, ao promover uma maior conscientização acerca das reais escolhas e motivações que levam essas mulheres a deixarem o mercado de trabalho, em função da maternidade. Para apresentar os resultados o texto foi organizado em cinco partes, incluindo esta introdução. A segunda parte é dedicada a expor o referencial teórico deste trabalho; a terceira apresenta a metodologia utilizada para realização da pesquisa de campo; a quarta trata da análise e discussão dos resultados, enquanto as considerações finais são fornecidas na última parte.

\section{REFERENCIAL TEÓRICO}

\subsection{As Mulheres e o Mercado De Trabalho}

Nas últimas décadas do século XX, o Brasil passou por importantes transformações demográficas, culturais e sociais que contribuíram para o aumento do trabalho feminino (BRUSCHINI; RICOLDI; MERCADO, 2008). Neste período observou-se uma queda na taxa de fecundidade, principalmente, nas regiões mais afluentes, uma redução no tamanho dos arranjos familiares e o envelhecimento da população com maior expectativa de vida para as mulheres. As transformações culturais e sociais, por sua vez, envolveram mudanças no papel social da mulher que se envolveu com o mercado remunerado. Associou-se a isso o aumento da escolaridade e o ingresso nas universidades, que viabilizaram o acesso das mulheres a novas oportunidades de trabalho.

Segundo Santos, Tanure e Carvalho Neto (2015), o que vem ocorrendo no Brasil é uma ampliação do campo de atuação feminina, em que as mulheres buscam, simultaneamente, a realização profissional e pessoal, a independência financeira e a preservação do papel de mãe. Ao acumular as funções das esferas púbica e privada, elas passaram a vivenciar uma dupla jornada de trabalho, com um primeiro turno dedicado à sua vida laboral, seguido por uma segunda jornada quando chegam à casa (NEVES; NASCIMENTO, 2018). Dado que, tradicionalmente, a mulher é vista como a principal responsável pelo cuidado e sustentação dos 
laços sociais, é ela quem recebe o ônus quando as demandas familiares atropelam as profissionais, ou vice-versa (BIROLI, 2018).

Dentre os fatores que dificultam a relação entre o trabalho e a família, está a desigual distribuição do trabalho doméstico entre homens e mulheres. Embora a participação dos homens no trabalho doméstico tenha aumentado nos últimos anos, ela ainda é bem inferior à das mulheres (NEVES; NASCIMENTO, 2018). Em 2019, o Instituto Brasileiro de Geografia e Estatística (IBGE) publicou que entre as pessoas de 14 anos ou mais, 92,2\% das mulheres realizam afazeres domésticos, contra 78,2\% dos homens, representando uma diferença de 14 pontos percentuais entre elas e eles (IBGE, 2019). Essa diferença de tempo e energia gera maiores dificuldades para as mulheres se dedicarem ao trabalho remunerado (BIROLI, 2018).

O desequilíbrio entre vida pessoal e profissional também pode estar diretamente relacionado com a intensificação do trabalho (GREEN, 2004; GASCOIGNE; PARRY; BUCHANAN, 2015). Executivos revelam que suas rotinas profissionais apresentam fortes pressões por resultados e jornadas com hora para começar, mas, frequentemente, sem hora para terminar. Não obstante o fato de tanto homens quanto mulheres participarem desse contexto, os impactos dessas condições de trabalho entre os gêneros são diferentes (LEMOS; CAVAZOTTE, 2018). Com o intuito de entregar os resultados almejados pelas organizações, as profissionais se envolvem com o trabalho de forma tão acentuada, que a vida profissional acaba invadindo a vida pessoal (LEMOS; GOTTLIEB; COSTA, 2016). Essa intensificação desfavorece as mulheres casadas, especialmente aquelas com filhos pequenos (GASCOIGNE; PARRY; BUCHANAN, 2015).

A questão da maternidade é o principal fator que demanda negociações no ambiente familiar e profissional. Hoje tem se observado um crescimento do número de gestações tardias, acima dos 35 anos e, dentre os motivos para tal tendência, encontram-se: a ampla disponibilidade de métodos contraceptivos, a postergação do matrimônio, a maior incidência de divórcios, o desejo de atingir um nível educacional e profissional mais elevado, de conquistar estabilidade e independência financeira, e o aprimoramento de técnicas de fertilização artificial (GOMES et al., 2008). Para Barbosa e Rocha-Coutinho (2007), o adiamento da maternidade acontece devido à entrada das mulheres das classes média e alta na esfera pública, principalmente daquelas que priorizam as suas carreiras. No entanto, a pesquisa de Carvalho Neto, Tanure e Andrade (2010) chama atenção para o fato de que a ação de postergar a maternidade para se dedicar à vida profissional pode ser fonte de angústia e sofrimento devido à pressão do relógio biológico. $O$ adiamento da maternidade tem levado mulheres a engravidarem em uma idade em que este processo já não é mais tão fácil, dada a queda de fertilidade que acompanha o envelhecimento feminino, em particular a partir dos 30 anos (NEVES; NASCIMENTO, 2017).

Para Lemos e Cavazotte (2018), há também mulheres sem filhos, que frequentemente relatam que a condição de longas jornadas de trabalho e tanta dedicação é transitória: só o fazem por não serem mães e consideram que, quando tiverem filhos, deixarão as suas profissões atuais e buscarão outras atividades que possibilitem conciliar o trabalho com a maternidade. De acordo com Morgado (2012), a necessidade de relacionar a vida pessoal e familiar e seus consequentes conflitos pode levar as gestoras de nível intermediário a optarem por não aceitar promoções para níveis mais altos na empresa, visto que consideram essa posição como limite do que consideram possível para administrar as duas esferas de forma equilibrada.

Além disso, de acordo com o estudo de Cuddy, Fiske e Glick (2004), existe uma visão de que a mulher, quando se torna mãe, passa a priorizar mais a família em detrimento do trabalho. Essa troca lhe custa credibilidade profissional e dificulta suas chances de ser contratada, promovidas e geralmente apoiadas no local de trabalho. Mães que trabalham, em comparação com pais que trabalham ou com mulheres sem filhos, são assumidas como mais distraídas pelos compromissos familiares e mais propensas a tirar licenças ou deixar o trabalho 
para se dedicar a seus filhos. Portanto, mesmo que não seja vista a perda de habilidades intelectuais ao ter um filho, a mulher com filhos pode ser percebida como uma perspectiva menos promissora de promoção ou compromisso de recursos da empresa.

Como atenuante desse desequilíbrio, algumas mulheres contam com o auxílio de membros da própria família, uma rede de apoio relativamente comum no Brasil, utilizada por casais com dupla carreira e filhos pequenos (DESSEN; BRAZ, 2000). Além disso, devido à disponibilidade dos serviços baratos de empregadas domésticas e babás, as mulheres também têm a possibilidade de terceirizar o cuidado da casa e dos filhos (CARVALHO NETO; TANURE; ANDRADE, 2010).

As famílias com condições financeiras contratam trabalhadores para a realização de tarefas domésticas - motoristas, governantas, babás, empregadas domésticas, amas de leite terceirizando, assim, boa parte das atividades de cuidados (HOCHSCHILD, 2012). Quanto mais entranhado na vida pessoal o mercado está, mais as pessoas se convencem de que precisam de serviços pagos para boa parte de suas necessidades pessoais (HOCHSCHILD, 2012). Para Hochschild (2012), as mães, carentes de tempo, estão sendo cada vez mais forçadas a escolher entre desempenhar o papel de mãe ou terceirizar uma parte desse papel.

Frente ao cenário exposto, muitas mulheres acabam abrindo mão de suas próprias necessidades. Atividades como ler, assistir televisão, visitar amigos, fazer exercícios ou mesmo ter tempo sozinha, passam a não existir em suas vidas (HOCHSCHILD, 2012). Foi nesse contexto de dificuldades de conciliar o trabalho e a vida familiar, e buscando entender a reação feminina contra esses impedimentos, que surgiu - nos Estados Unidos - o termo opt-out.

\subsection{O Fenômeno Opt-out e os Desafios da Maternidade em Período Integral}

A expressão "opting out" surgiu quando Belkin (2003) publicou no The New York Times Magazine uma matéria sobre 10 mulheres formadas em renomadas universidades americanas, que tiveram êxito em suas carreiras e optaram por sair do mercado de trabalho para cuidar dos filhos. Além de basear sua tese nas histórias dessas mulheres, Belkin (2003) apresentou dados estatísticos do Censo dos Estados Unidos que mostravam uma redução do número de mulheres que retornaram ao mercado de trabalho, de $59 \%$ em 1998 para 55\% em 2000, e o aumento de $13 \%$, em menos de 10 anos, do número de crianças cuidadas por mães que estavam em casa. Belkin (2003) argumentou que mulheres qualificadas e bem-sucedidas profissionalmente podem pagar por sua liberdade de escolha.

A maioria das pesquisas relacionadas ao movimento opt-out está ligada a imagens tradicionais de mulheres heterossexuais, brancas, de classe média alta e casadas; o que relaciona tal decisão a privilégios de classe e raça (AKASS, 2012). Essas mulheres não estão associadas à feminilidade passiva, remontando a um estado "natural" de domesticidade (AKASS, 2012), mas incorporam o que Gill (2007) chama de "uma sensibilidade pós-feminista": um sujeito materno contemporâneo ativo, que opta exclusivamente por ser mãe e se retira do mercado de trabalho. Ela não é uma trabalhadora produtiva que contribui diretamente para a economia neoliberal, mas incorporaria os valores neoliberais / pós-feministas de escolha, agência, individualização e libertação feminina (AKASS, 2012; ORGAD; DE BENEDICTIS, 2015).

Para Biese (2017), o movimento opt-out envolve uma opção por deixar regras, estruturas, tradições e expectativas que a sociedade, a cultura e as organizações impõem aos indivíduos. A autora define o fenômeno como o movimento pelo qual as mulheres deixam suas carreiras tradicionais, para viverem sob seus próprios termos. Segundo a autora, essas mulheres têm credenciais para serem profissionais iguais aos homens no mercado de trabalho, mas interrompem suas carreiras por sentirem que os malabarismos que precisam fazer para conciliar as demandas da carreira e dos filhos não valem à pena.

$\mathrm{Na}$ visão de Stone (2007), as adeptas ao fenômeno opt-out tendem a usar a retórica da escolha a serviço de sua excepcionalidade, relacionando-a ao privilégio da classe social, ao 
feminismo e à agência pessoal. Essa foi uma combinação atraente, que contribuiu para a decisão e, também, serviu para compensar a perda das carreiras que amavam e das identidades profissionais que valorizavam (STONE, 2007).

Diversos estudos relacionados ao tema opt-out buscaram compreender os fatores que levaram as mulheres a interromperem carreiras estruturadas e bem remuneradas para a dedicação exclusiva à maternidade. Essas pesquisas identificaram que não só o desejo de se dedicar integralmente à maternidade motivou tal afastamento do mercado de trabalho, mas também fatores associados ao trabalho, aos filhos e aos companheiros (STONE; LOVEJOY, 2004; STONE, 2007; MAINIERO; SULLIVAN, 2006; CABRERA, 2007; MCKIE; BIESE; JYRKINEN, 2013; BIESE, 2017).

As razões relacionadas ao trabalho que influenciam a decisão de interrupção da trajetória profissional estão associadas à quantidade, ao ritmo e à inflexibilidade do trabalho; à inadequação de opções de jornadas reduzidas; à falta de oportunidades de promoção e de trabalho interessante (STONE; LOVEJOY, 2004; CABRERA, 2007; STONE, 2007; ELY, STONE, AMMERMAN, 2014; MCKIE; BIESE; JYRKINEN, 2013; BIESE, 2017). De acordo com a pesquisa de Ely, Stone e Ammerman (2014), apenas um pequeno número de mulheres com MBA da renomada Harvard Business School deixam as suas carreiras porque gostariam de se dedicar integralmente aos filhos. A grande maioria parte com relutância porque se vê exercendo papéis insatisfatórios e com perspectivas sombrias de progresso. A mensagem de que não são mais consideradas "jogadoras" é comunicada de várias maneiras, às vezes sutis: elas são estigmatizadas por optarem por horários flexíveis ou reduzidos (STONE; HERNANDEZ, 2013; ELY, STONE, AMMERMAN, 2014; STONE; LOVEJOY, 2019); por serem preteridas em tarefas de alto perfil ou removidas dos projetos que antes lideravam (ELY, STONE, AMMERMAN, 2014; STONE; LOVEJOY, 2019). O estudo de Cabrera (2007) também constatou a demissão e a desilusão com a cultura corporativa como fatores condicionantes da decisão de mulheres pela interrupção de suas carreiras. Stone e Lovejoy (2019) identificaram que nove em cada dez mulheres relacionam as suas decisões de interromper a carreira ao lado profissional e não ao familiar. O preço do sucesso para elas era o que muitas chamavam de tudo ou nada no trabalho, caracterizado por longas jornadas e demandas implacáveis (STONE; LOVEJOY, 2019).

As mulheres que optaram por sair do trabalho por causa dos filhos foram motivadas tanto pelos cuidados dos filhos pequenos, como pelos mais velhos, em idade escolar (STONE; LOVEJOY, 2004). As atraídas pelos filhos pequenos primaram pelo cuidado parental no início da vida de uma criança e pelo apego e vínculo pelo bebê que dificultaram o retorno ao trabalho (STONE; LOVEJOY, 2004). No tocante aos filhos mais velhos, um aumento da complexidade das demandas percebidas em relação às crianças mais novas, bem como a dúvida sobre a capacidade de seus cuidadores remunerados ajudá-los, acarretam a interrupção das carreiras das mulheres (STONE; LOVEJOY, 2004). Embora no Brasil a disponibilidade de mão de obra de empregadas domésticas e babás seja de mais fácil acesso, a transmissão de educação e dos valores é atribuída aos pais (CARVALHO NETO; TANURE; ANDRADE, 2010).

Já os motivos referentes aos companheiros, incluem a falta da participação deles nas tarefas domésticas e de cuidado dos filhos, ao fato da renda da mulher ser vista como secundária, à preferência de alguns por terem suas esposas em casa, e a necessidade de realocação geográfica devido ao emprego de maior prestígio do cônjuge (STONE; LOVEJOY, 2004). A pesquisa de Baker (2010) mostrou que, dez anos após o recebimento de um diploma, as mulheres tinham uma probabilidade três vezes maior de estarem fora do mercado de trabalho do que os homens, e citaram, predominantemente, as responsabilidades familiares como a principal razão disso.

Além disso, quando a diferença salarial entre o homem e a mulher é considerada na família, o salário menor da mãe é sacrificado (VAVRUS, 2007). Essa priorização da carreira 
dos companheiros não apenas reafirma a natureza complexa das decisões de carreira das mulheres, como também contribui para a carreira sequencial dos homens (VAVRUS, 2007). Desta forma, embora eloquente, a narrativa opt-out colabora para ocultar o grande diferencial de poder existente entre pais e mães, uma vez que a "escolha" realizada individualmente pelas mulheres é avaliada, reconhecida e endossada (ORGAD; DE BENEDICTIS, 2015).

Diante desses aspectos, pesquisas críticas apontam que a narrativa opt-out mascara, racionaliza e desculpa práticas no local de trabalho, e na sociedade em geral, que discriminam mulheres e mães (VAVRUS, 2007; STONE, 2007; AKASS, 2012), ao presumirem que qualquer desequilíbrio seja diretamente atribuível às "escolhas" delas, que são apresentadas como um assunto privado (VAVRUS, 2007; STONE, 2007; AKASS, 2012; LEWIS; BENSCHOP; SIMPSON, 2017). Levando isso em conta, percebe-se como o movimento optout contribui para a manutenção do status quo. Reconhecer que as desigualdades estruturais e a discriminação sistemática nas organizações violam as normas de igualdade é muito menos atraente do que o apelo à agência e à autodeterminação que tornam a escolha individual uma retórica tão poderosa (LEWIS; BENSCHOP; SIMPSON, 2017). Diante da falta de alternativas para permanecerem em suas trajetórias profissionais, muitas mulheres interrompem as suas carreiras para se dedicarem exclusivamente aos filhos.

Uma vez em casa, para muitas mulheres adeptas ao movimento opt-out, o momento inicial, após a interrupção de carreira, foi preenchido por um sentimento de alívio, já que muitas delas trabalhavam pelo menos 40 horas semanais, além das inúmeras horas adicionais em casa (MCGRATH; DRISCOLL; GROSS, 2005; BIESE, 2017). Entretanto, em seguida, elas se deparam com o processo de estar em casa, também cheio de dificuldades, e passível de produzir crises de identidade (STONE, 2007, BIESE, 2017). Ao longo do período de dedicação à carreira profissional, a vida e a identidade das mulheres eram definidas pelo trabalho. A partir do momento em que elas deixam o mercado de trabalho, precisam lidar com o desafio de adotar a identidade de estar em casa, não muito valorizada perante a sociedade contemporânea (STONE, 2007).

A estrutura e a organização de suas novas vidas - agora centradas na família provocaram profundas mudanças em seus valores, interesses e prioridades (LOVEJOY; STONE, 2012). As mulheres vivenciam o que Stone e Lovejoy (2019) denominam de "domesticidade privilegiada". Com o passar do tempo, em suas novas vidas como mães que estão em casa, totalmente dedicadas aos filhos, criam um alto envolvimento com a maternidade e com a casa, enquanto os maridos investem em suas carreiras e trazem dinheiro para o lar. Essas mulheres não são apenas mães que estão em casa; são coreógrafas de atividades extracurriculares, treinadoras e defensoras de suas crianças e planejadoras da vida doméstica de toda a família (STONE; LOVEJOY, 2019). Além disso, elas têm a possibilidade de pagar a outras pessoas para realizarem o trabalho doméstico, podendo se concentrar mais nos compromissos prazerosos (LOVEJOY; STONE, 2012).

No entanto, mesmo com os privilégios de estar em tempo integral com os filhos, as mulheres expressavam um sentimento de estagnação profissional, o que gerava nelas uma baixa autoestima e medo de como seria o futuro (LOVEJOY; STONE, 2012). Ademais, devido às grandes demandas e extensas jornadas de trabalho dos companheiros, notou-se uma menor disponibilidade e vontade por parte deles em lidar com as responsabilidades familiares (STONE; LOVEJOY, 2019). Em seu papel de mães em período integral, as opções das mulheres foram ainda mais limitadas por sua perda de poder de barganha. Algumas observaram que seus maridos simplesmente pararam de ajudar nas tarefas domésticas, que passaram a ser vistas como de domínio delas, por estarem mais tempo no lar (LOVEJOY; STONE, 2012). Mesmo que a domesticidade privilegiada seja sedutora e recompensadora de várias maneiras, ela também contribuiu para o aumento da dependência e da subordinação das mulheres dentro 
da família, o que torna o oportuno retorno ao trabalho mais árduo e menos provável (STONE; LOVEJOY, 2019).

\section{ASPECTOS METODOLÓGICOS}

De forma a alcançar o objetivo desta pesquisa foram entrevistadas, presencialmente, 14 mulheres, com formação superior e pós-graduação, residentes nas cidades do Rio de Janeiro e São Paulo, e que atuaram em ambientes organizacionais de segmentos diferentes do mercado privado. Todas as entrevistadas suspenderam suas carreiras consolidadas para cuidar exclusivamente dos filhos e, após um período, retornaram para o mercado de trabalho. A seleção das entrevistadas foi feita por meio de círculos de amizades das autoras, complementado pela técnica bola de neve (BERNARD, 2005). O quadro 1, a seguir, sintetiza o perfil das entrevistadas, que são identificadas por nomes fictícios.

\begin{tabular}{|c|c|c|c|c|c|}
\hline $\begin{array}{c}\text { Nome } \\
\text { (fictícios) }\end{array}$ & $\begin{array}{l}\text { Qtd. } \\
\text { filhos }\end{array}$ & $\begin{array}{c}\text { Área de } \\
\text { Formação }\end{array}$ & $\begin{array}{l}\text { Idade quando } \\
\text { interrompeu a } \\
\text { carreira }\end{array}$ & $\begin{array}{c}\text { Tempo de } \\
\text { interrupção }\end{array}$ & Ocupação Atual \\
\hline Beatriz & 3 & Direito & 38 anos & 6 anos & Advogada \\
\hline Sofia & 2 & Administração & 28 anos & 2 anos & Professora \\
\hline Laila & 2 & Direito & 30 e 38 anos & 2 anos; 1 ano e meio & Arquiteta \\
\hline Ariel & 1 & Administração & 30 anos & 1 ano & Professora \\
\hline Luna & 3 & Arquitetura & 33 anos & 3 anos e meio & Arquiteta \\
\hline Cristina & 2 & Administração & 39 anos & 3 anos & Gerente de Produto \\
\hline Luiza & 3 & Moda e Diteiro & 30 anos & 2 anos e meio & Advogada \\
\hline Fabiana & 2 & Administração & 32 anos & 5 anos & Gerente de recrutamento \\
\hline Gabriela & 1 & Pedagogia & 32 anos & 5 anos e meio & Pedagogia \\
\hline Clarissa & 2 & Administração & 40 anos & 3 anos e meio & Gerente de Marketing \\
\hline Paula & 2 & Administração & 31 anos & 4 anos & Diretora de marketing \\
\hline Anne & 2 & Administração & 38 anos & 6 anos & Consultora \\
\hline Ana & 1 & Administração & 32 anos & 1 ano e meio & Professora \\
\hline Marcia & 2 & Engenharia civil & 33 anos & 4 anos & Engenheira Civil \\
\hline
\end{tabular}

Fonte: Elaboração das autoras

As entrevistas foram guiadas por um roteiro aberto, iniciadas com a seguinte questão: me conte sobre a sua trajetória de carreira, explorando, principalmente, os seguintes assuntos: as razões que levaram a interrupção da carreira, após o advento da maternidade; o período de dedicação integral aos filhos; e os desafios da fase atual. As conversas duraram cerca de 30 minutos, ocorreram presencialmente, e foram gravadas e transcritas com o consentimento das entrevistadas.

Para análise do material coletado em campo foi utilizado o método análise de conteúdo qualitativa, que seguiu os procedimentos de Bardin (2016). Esse procedimento foi aplicado ao material transcrito, a partir dos áudios das entrevistas, e, em seguida, foi feita uma análise temática, com base em quatro categorias definidas a priori (baseado na leitura prévia sobre o tema opt-out). Três categorias - os obstáculos do mundo do trabalho; o exercício da maternidade; e a ausência paterna - exploraram os fatores condicionantes que levaram as entrevistadas a aderirem ao fenômeno opt-out, enquanto a quarta e última categoria - os desafios da maternidade em período integral - compreendeu as vivências após a interrupção de carreira dessas mulheres, no período de dedicação exclusiva à maternidade. 


\section{ANÁLISE E DISCUSSÃO DOS RESULTADOS}

O presente estudo buscou identificar os motivos que levaram mulheres a aderirem ao movimento opt-out, assim como suas vivências no decorrer do período de dedicação integral à maternidade. Embora todas as entrevistadas tenham deixado o mercado de trabalho para cuidar dos filhos, os resultados desse estudo revelaram os fatores condicionantes de tal decisão. Tais fatores estão apresentados nas três primeiras categorias: 1) os obstáculos do mundo do trabalho; 2) o apelo do exercício da maternidade e 3) a ausência dos pais. A quarta e última categoria, desafios e seduções da maternidade em período integral, investiga as vivências das entrevistadas no período de dedicação exclusiva aos filhos.

\subsection{Categoria 1 - Os Obstáculos do Mundo do Trabalho}

Aspectos relacionados às condições de trabalho foram relevantes para a decisão de interrupção da carreira para grande parte das entrevistadas. Muitas delas deixaram seus trabalhos, porque dispuseram de poucas opções para conciliar as intensas demandas de carreira com a maternidade. Embora o alto poder aquisitivo dessas mulheres tenha sido um requisito para a tomada de decisão, esta "não se tratava de uma preferência, mas uma decisão do tipo tudo ou nada, necessária à natureza do tudo ou nada do trabalho" (STONE; LOVEJOY, 2019, p.43).

Uma importante razão mencionada pelas mulheres entrevistadas, que motivou a interrupção de suas carreiras, foi o conflito gerado quando se tem uma quantidade exorbitante de trabalho e a necessidade de atender às demandas da vida familiar (STONE; LOVEJOY, 2004). Os relatos a seguir estão diretamente relacionados aos problemas encontrados pelas mulheres advindos da sobrecarga de trabalho vis-à-vis a maternidade:

\footnotetext{
"Fechava a porta do departamento às 17:00 horas, mas eu continuava a trabalhar e ficava atendendo, atendendo, atendendo. O meu marido, na época, falou: você não vê o nosso filho, você não come, você não dorme..." (Cristina).

“... eu ia deixar aquele bebezinho em casa, sendo cuidado por outras pessoas e ir pro esquema "pague pra entrar, reze pra sair"... Eu pude ser uma das privilegiadas $e$ afortunadas em falar, "vou parar"”, (Beatriz).
}

Ademais, algumas mulheres trabalhavam em locais onde o ritmo e as expectativas eram fixados pelos homens. Beatriz, advogada, contou que trabalhava em um ambiente predominantemente masculino e percebia o quanto a diferença de responsabilidades dela para os homens, pelo fato de ser casada e com filhos, afetava o seu cotidiano: "Eu estava ali ombro a ombro com um bando de homens... eu era bem novinha, mas eu já tinha uma filha e uma casa pra cuidar. O pessoal ali era pessoal que nem casado era, que o milagre da roupa acontecia, né?" (Beatriz).

Em linha com a literatura (LEMOS; CAVAZOTTE, 2018), algumas entrevistadas, que cumpriam jornadas de trabalho intensas antes da maternidade e anteviam que o tempo dedicado ao trabalho comprometeria o tempo que seria destinado aos filhos quando fossem mães, já tinham decidido que interromperiam suas carreiras, quando os filhos nascessem:

\footnotetext{
"Ser mãe e comissária de bordo, pra mim, era claro que não dava. Eu tinha que parar de ser comissária pra poder ser mãe” (Ariel).

"Eu conhecia algumas mulheres do escritório e escutava as histórias delas sobre maternidade... via no olhar delas um pouquinho de sofrimento, uma coisa meio frustrada. Então isso pra mim foi muito bom, porque foi uma experiência prévia pra me dar certeza de que eu não queria continuar ali depois que eu tivesse filho” (Lívia).
}

A falta de alternativas flexíveis oferecidas pelas organizações, como trabalho de meio período ou home office, que permitissem a conciliação das demandas profissionais e familiares 
foi mencionada por elas como um dos fatores que as levaram a interromper as suas carreiras (STONE; LOVEJOY, 2004). Os relatos a seguir evidenciam que elas não se afastaram de seus trabalhos porque escolheram, mas porque não encontraram opções reais de escolha para continuar trabalhando:

\footnotetext{
“... eи e meu chefe tentamos montar um esquema de home office, mas a verdade é que ele não queria ter alguém longe" (Paula).

"Antes de pedir demissão, pedi até licença não remunerada, pedi tudo. A empresa estava com todos os processos suspensos nesse sentido" (Fabiana).
}

Outro motivo que levou as mulheres a interromperem as suas carreiras está relacionado às barreiras que elas encontraram para ascender profissionalmente (ELY, STONE, AMMERMAN, 2014). Esta dificuldade impactou negativamente a vida corporativa de Marcia, quando, depois que se tornou mãe, sentiu que suas chances de promoção e de reconhecimento diminuíram: "Quando eu fui participar de um novo projeto, tinha um cara que entrou junto comigo na empresa e ele estava a dois níveis acima do meu. Claro que estava dois níveis acima do meu, eu já tinha dois filhos" (Marcia).

O tratamento desigual de gênero sofrido por Marcia no local de trabalho, em função da maternidade, a fez perceber o quão difícil é para uma mulher ocupar cargos de gestão sendo mãe e como os homens não vivenciam essa experiência. Este tratamento diferenciado culmina na insatisfação com o trabalho e consequente interrupção de carreira (ELY; STONE; AMMERMAN, 2014).

\footnotetext{
"Fui me frustrando com a forma com que a empresa me tratava pós-maternidade. Aquela profissional que eu queria ser morreu depois que eu fui mãe, porque eu percebia que eu não poderia ser diretora se eu fosse mãe. Por isso que você vai vendo que tantos homens vão indo e a gente vai ficando" (Marcia).
}

A dificuldade de ascensão na carreira vivenciada por Marcia, após a maternidade, está em linha com a pesquisa de Cuddy, Fiske e Glick (2004), que indicou que depois de se tornar mãe, a mulher perde credibilidade profissional e reduz sua chance de ser promovida e apoiada no local de trabalho.

A demissão não planejada, como apontado no estudo de Cabrera (2007), foi também um fator analisado neste estudo, que contribuiu para a suspensão da carreira das mulheres. Com a saída involuntária das empresas, as entrevistadas estenderam o período em casa para se dedicar à maternidade, antes de tentar voltar para o seu cotidiano profissional:

\footnotetext{
"Quando eu fui demitida... eu saí de licença maternidade e não voltei mais" (Anne). "Eu não planejei isso, não teria parado. Houve uma série de demissões na empresa e eu fui uma delas” (Luna).
}

Por fim, e como contribuição ao debate sobre o fenômeno opt-out, está o longo tempo despendido durante o trajeto casa-trabalho como fator que motivou as mulheres a deixarem as suas carreiras para se dedicarem à maternidade. As grandes distâncias entre o lar e o local de trabalho, somadas ao trânsito congestionado das cidades grandes, são responsáveis por um considerável tempo no dia a dia das profissionais:

\footnotetext{
"Foi mais o afastamento de casa que me atrapalhava. Eu cheguei a pensar em me mudar pra tentar ficar mais perto, mas isso não era viável” (Sofia).

"Eu trabalhava longe da minha casa. Morava no Humaitá e a empresa era na Barra, depois a empresa mudou de lugar e ficou mais longe ainda. Então eu não via o meu filho" (Cristina).
} 
Portanto, os achados discutidos nesta categoria sugerem que a decisão das mulheres de suspenderem as suas carreiras foi fortemente moldada pelas condições de trabalho que são desfavoráveis para a continuidade das atividades profissionais após o advento da maternidade. Esse resultado vai de encontro ao proposto por Belkin (2003), que sugere que as mulheres estão interrompendo suas carreiras porque desejam cuidar dos filhos em tempo integral.

A grande maioria das mulheres pesquisadas tinha carreiras em grandes organizações, viajou pelo mundo, trabalhou duro e ganhou altos salários. No entanto, com o nascimento dos filhos, elas consideraram que as demandas profissionais eram incompatíveis com a criação de uma família. Assim, o fato delas pararem de trabalhar para se dedicarem unicamente à maternidade vai de encontro ao senso de identificação delas com as suas carreiras e aos pesados investimentos feitos por elas, que incluem não apenas experiência profissional, mas também cursos de pós-graduação (STONE, 2007). Para muitas, deixar o emprego não foi fácil, uma vez que elas se orgulhavam de suas conquistas profissionais.

\subsection{Categoria 2 - O Exercício da Maternidade}

Em linha com o fenômeno opt-out, Gabriela foi a única mulher entrevistada que manifestou o desejo de exercer unicamente a maternidade, por considerar importante a presença dos pais, sobretudo das mães, nos primeiros anos da vida dos filhos (STONE; LOVEJOY, 2004). Gabriela não teve dúvidas quando decidiu deixar a sua carreira profissional ainda antes do seu filho nascer, para se dedicar a fase inicial da vida dele: "Estava numa fase profissional muito boa, mas eu não tive a mínima dúvida de que eu queria parar... Então, eu pedi demissão. E eu queria aproveitar o meu filho, queria curtir ele..." (Gabriela).

Já Clarissa, apesar de ter afirmado que gostaria de exercer, simultaneamente, as funções de mãe e profissional, depois de um determinado período percebeu que não conseguiria atender às duas esferas com a qualidade que gostaria, optando por cuidar das filhas. Ela tomou essa decisão por acreditar que a dedicação exclusiva à função materna geraria um diferencial na formação dos valores e no desenvolvimento delas: "... eu queria fazer a minha parte de tentar educá-las pra que elas sejam, sei lá, pessoas do bem, pessoas que pensem no próximo, que tenham responsabilidade" (Clarissa).

Outra motivação para a dedicação integral à maternidade, identificada nos relatos, está relacionada às experiências vivenciadas pelas entrevistadas antes e durante a maternidade. A dificuldade para engravidar foi uma das experiências que gerou um desejo particularmente forte nas mães de aproveitar cada segundo da vida de seus esperados bebês:

\footnotetext{
"Eu me surpreendi com a dificuldade de conseguir engravidar. Eu fiz tratamento, eu fiquei naquela coisa de que espera todo mês e aí não acontece. Meu filho foi muitíssimo esperado. Quando eu tive ele quis aproveitar tudo" (Gabriela).

"Durante cinco anos, fiz 13 tratamentos para engravidar e nenhum deles deu certo. E aí, num belo dia, me vi grávida, naturalmente. Eu não acreditava ser possível. Eu queria ser, acho que por tudo o que eu passei, uma mãe presente” (Clarissa).
}

É válido mencionar que, tanto Gabriela como Clarissa, engravidaram após os 30 anos de idade, faixa em que a mulher já apresenta uma queda na taxa de fertilidade (NEVES; NASCIMENTO, 2017). São mulheres, que ao longo de suas trajetórias de vida, experimentaram momentos profissionais de rápido crescimento, o que as levou a fazer outras escolhas e a adiar a maternidade no período em que eram mais novas e mais aptas a terem filhos. Vale destacar que tal opção não significa uma recusa em ter filhos, mas demonstra a dificuldade das mulheres em conciliar todas as responsabilidades de sua vida ao mesmo tempo.

Algumas participantes desta pesquisa também demonstraram dificuldades de passar pela fase do puerpério, um período que pode ser muito doloroso para as mulheres. As 
dificuldades de amamentar, de lidar com as mudanças do corpo, de não dormir direito, entre outras, podem gerar um conflito interno nas mulheres e levá-las a interromperem suas carreiras:

\begin{abstract}
"A maternidade foi uma puxada de tapete, que eu não tinha ideia... Eu realmente me vi no puerpério, me vi desestruturada. Eu era super independente e me sentia superpoderosa para fazer as coisas, e do nada me vi com um bebezinho no colo, super frágil" (Paula).

"Eu queria muito continuar a amamentar. Na empresa não tinha lugar pra ficar tirando leite e guardar na geladeira. Eu quase entrei em depressão. Eu ia trabalhar, meu peito ficava duro, doendo, às vezes. Até febre eu tinha de tanto leite. Eu achava aquilo uma agressão em relação mãe e filha" (Marcia).
\end{abstract}

A abdicação dos serviços terceirizados para cuidado dos filhos, como creches e babás, foi outro motivo que levou as participantes desta pesquisa a se afastarem de suas trajetórias profissionais. Ao abrirem mão voluntariamente desta assistência, o serviço de cuidado tende a ficar com elas:

\begin{abstract}
"Eu não queria deixar o meu bebê numa creche com quatro meses, quando a minha licença acabasse... Eu queria me dedicar ao meu filho, queria curtir ele." (Gabriela). "Eu tinha uma demanda específica de um bebê pequeno, que, em muitos momentos, eu não queria terceirizar" (Ana).
\end{abstract}

Gabriela e Ana tinham condições financeiras para terceirizar qualquer serviço de cuidado que as possibilitasse ter mais tempo para equilibrar as demandas das esferas pública e privada. No entanto, elas rejeitaram a mercantilização da vida familiar (HOCHSCHILD, 1997, 2012) e optaram por interromper suas carreiras para se dedicarem integralmente aos filhos. Demandas especiais de cuidados, ocasionadas por problemas de saúde dos filhos, também desencadearam afastamentos involuntários das mães do mercado de trabalho.

\footnotetext{
"Eu tive que parar por uma necessidade mesmo. O meu filho nasceu prematuro, ficou internado na UTI três meses, e depois foi uma agenda em torno dele" (Laila).

"Veio o diagnóstico de que o meu filho tinha uma questão respiratória muito crítica... E aí foi a "opção", né? Ou eu continuava a trabalhar, ou eu cuidava do meu filho" (Fabiana)
}

Desta forma, as entrevistadas que se afastaram de suas carreiras, devido à vontade de se tornarem mães em tempo integral, parecem referendar que as atividades relacionadas aos cuidados com os filhos deveriam ser exercidas por elas. Elas raramente aceitaram ajuda terceirizada e se engajaram na criação dos filhos, acompanhando de perto desenvolvimento deles (LOVEJOY; STONE, 2004). No entanto, vale ressaltar, que a saída do mercado de trabalho em função de problemas de saúde das próprias mulheres (puerpério e depressão), fator não encontrado na literatura sobre opt-out, não ocorreu por uma vontade de exercer plenamente a maternidade, mas por uma real necessidade.

\title{
4.3. Categoria 3 - A Ausência Paterna
}

A expectativa tradicional do papel de gênero, que pressupõe que as mulheres estejam em casa para cuidarem dos filhos enquanto os homens trabalham e trazem dinheiro para o lar (VAVRUS, 2007), internalizada por grande parte da sociedade brasileira, foi uma das razões mencionadas pelas entrevistadas que as levou a aderir ao movimento opt-out.

"O meu marido é participativo, mas existe uma naturalização de que eu faço melhor" (Ana).

"Era tudo comigo e com a enfermeira. O meu marido não sabia fazer nada” (Luiza). 
Além disso, a intensa rotina de trabalho dos companheiros (mesmo quando equiparada à intensidade da rotina das entrevistadas) surgia nas narrativas como justificativa para a ausência dos mesmos no cuidado das crianças e nas tarefas domésticas (STONE; LOVEJOY, 2004):

\footnotetext{
"Meu marido trabalhava que nem um louco alucinado, e eu que nem uma louca alucinada. Ele não participava da vida cotidiana do lar, no sentido de me ajudar. Não existia isso" (Beatriz).

"Eu acostumei o meu marido muito mal. Como ele sempre trabalhou muito, eu acabei pegando todas as responsabilidades pra mim, fazia absolutamente tudo" (Laila).
}

Todas as participantes desse estudo eram casadas com homens com empregos como os seus, com longas jornadas e muitas viagens. Todavia, em linha com a literatura (BIROLI, 2018), a distribuição desigual de trabalho doméstico e de cuidado entre homens e mulheres fez com que elas enfrentassem grandes dificuldades para se dedicarem ao trabalho remunerado. Assim, os resultados desta pesquisa corroboram o entendimento de que a adesão ao fenômeno opt-out acarreta a priorização das carreiras masculinas e o retorno das mulheres ao lar, mascarando o grande diferencial de poder existente entre os sexos (STONE; LOVEJOY, 2019).

\subsection{Categoria 4 - Desafios da Maternidade em Período Integral}

Após o afastamento do mercado de trabalho, em um primeiro momento, algumas entrevistadas expressaram um sentimento de libertação por estarem em casa com seus filhos. Emoções positivas são esperadas neste momento, uma vez que muitas profissionais trabalhavam pelo menos 40 horas semanais, além das inúmeras horas adicionais em casa (McGrath, Driscoll; Gross, 2005). As falas seguintes evidenciam essa sensação:

\footnotetext{
"Foi um momento assim... de libertação, de tudo" (Laila).

"eu me lembro dando a notícia pro meu ex-marido, "vamos comemorar"” (Anne).
}

Entretanto, em seguida, as participantes desta pesquisa se deparam com uma experiência cheia de provações, passíveis de produzir crises de identidade. Elas precisaram reconstruir a identidade que era centrada no trabalho, para outra de estar em casa para cuidar da família, papel que, além de não ser muito valorizado perante a sociedade, era uma novidade para algumas mulheres (STONE, 2007):

\footnotetext{
"De repente, eu me vi tendo que fazer mercado, pensar em almoço, jantar, ainda tinha as crianças. Então assim, era uma identidade que eu não me identificava” (Anne).

"A minha angústia era muito de tentar entender o que era essa vida nova, o que era cuidar de filho, o que era ser mãe, o que era organizar uma casa que eu não organizava antes. A sensação é que eu tinha morrido e estava nascendo de novo, ou que eu tinha viajado pra outro planeta” (Paula).
}

Com a adaptação ao lar, a organização da nova vida provocou alterações nos interesses e valores das entrevistadas (LOVEJOY; STONE, 2012). Elas desenvolveram um alto envolvimento com a maternidade e com trabalhos voluntários e tarefas domésticas, e terceirizaram os serviços menos prazerosos. A esta experiência vivenciada pelas mulheres, Stone e Lovejoy (2019) denominam de "domesticidade privilegiada". A falas seguintes indicam que as entrevistadas reconheceram os prazeres deste período:

"Eu me sentia muito feliz e realizada de estar podendo viver aquilo. Eu vivi muito intensamente e tudo" (Livia).

"Eu realmente estava muito feliz trocando as fraldas, botando pra dormir, cantando pra elas e... eu realmente me encontrei também nessa nova função” (Clarissa). 
"Eu fui chamada pra dar palestra pras mães, pras grávidas, de tanto que eu me envolvi com a maternidade" (Ariel).

Apesar de a vivência da domesticidade privilegiada ser sedutora e recompensadora, ela também ocasiona um cansaço extremo nas mulheres que se dedicam unicamente aos filhos (STONE; LOVEJOY, 2019): "Eu só fiquei seis anos mãe, mãe, mãe. Eu lembro quando eu tirava foto de mim enlouquecida e mandava para o meu marido, "eu não aguento mais. Isso aqui é vida real"," (Anne).

Ademais, para muitos companheiros, as tarefas domésticas passam a ser de domínio unicamente feminino, uma vez que as mulheres estão em casa (LOVEJOY; STONE, 2012). O relato de Ariel demonstra esse entendimento: "Eu falava, "não quero que ajude, eu quero que divida", e ele falava, "ah, mas eu trabalho o dia inteiro, eu não estou em casa", "eu também trabalho o dia inteiro, eu estou em casa"", (Ariel).

Também foi observada, na análise das entrevistas, a perda da autonomia financeira de algumas mulheres. Cristina expôs a sua delicada experiência de depender financeiramente do companheiro: "As minhas coisas ninguém nunca pagou, então, quando eu parei de trabalhar e usava o cartão do meu marido. Isso me incomodou demais, foi desesperador" (Cristina). Esta dependência piorou, quando o marido de Cristina decidiu se separar: "Quando o meu marido decidiu se separar, eu estava afastada do trabalho, e me vi totalmente dependente e refém dele. Foi o pior momento da minha vida" (Cristina).

Atritos narrados pelas entrevistadas sobre o casamento foram decorrentes, principalmente, do cansaço do dia a dia da casa, dos filhos e da baixa autoestima:

\footnotetext{
"Quando você se deprime, quando você não se sente o que gostaria de ser, não se valoriza, você se recolhe. Então, assim, o abalo na relação foi da minha parte..." (Luna).

"Foi dificil para o casamento... quando o meu marido chegava do trabalho, eu não aguentava mais assim, eu estava exausta por cuidar de um bebê... eu cobrava por mais participação dele... mas, de fato, ele sempre foi um super parceiro" (Paula).
}

Sobre estes relatos, vale ressaltar como algumas mulheres atribuem unicamente a si a responsabilidade pelo desajuste matrimonial, mesmo sendo elas, e não eles, que abriram mão de suas carreiras para viver um modelo centrado na família, e experimentaram a exaustão de cuidar de um bebê $100 \%$ do seu tempo.

A importância do trabalho na vida das entrevistadas pode ser percebida quando elas narraram que se sentiram improdutivas e culpadas por não estarem trabalhando durante o momento de dedicação integral aos filhos. De acordo com Biese (2017), contemporaneamente as mulheres são ensinadas que podem ter tudo, porém se sentem frustradas, quando constatam que não podem administrar todas as demandas de sua vida:

\footnotetext{
"As minhas amigas que tinham filhos e trabalhavam, falavam pra mim, "eu invejo você porque você pôde dar esse refresco na tua vida e cuidar dos teus filhos durante essa primeira infância. Que sorte a sua". Eu nunca achei que isso fosse sorte. Eu agradeço por isso, mas, ao mesmo tempo, eu falava pra elas, "vocês não sabem a culpa que eu vivo", porque é uma culpa assim, "até quando? Como é que vai ser?"." (Beatriz).

"Nunca foi tranquilo, "ah, eu tô aqui de boa". Eu não estava ok com não estar produzindo, com não estar inserida” (Paula).
}

O medo de não conseguir voltar a trabalhar, resultante do estigma empresarial existente contra as mães no local de trabalho, da desatualização profissional, da perda de autoconfiança e de network, depois de um período fora do mercado de trabalho, também se fez presente para as entrevistadas: 


\begin{abstract}
"Eu falei, "caramba, daqui a pouco eu vou ser uma pessoa que não vai conseguir sair do desemprego, ou vai ter que voltar pro mercado numa posição muito inferior, porque ficou muito tempo parada, e o mercado não vê isso de uma forma positiva... vê como uma estagnação" (Sofia).

"Eu sentia tristeza porque eu estava... na verdade, saindo de um mercado que eu gosto, e aí bate o medo de não conseguir voltar, de eu tá me afastando do mercado, né?" (Laila).
\end{abstract}

Diante desses relatos, é importante notar como as atividades relacionadas ao trabalho de reprodução social não têm seu valor reconhecido por grande parte da sociedade (incluindo homens e mulheres), quando comparadas ao trabalho de produção econômica. Embora o trabalho de cuidado esteja ligado à perpetuação da existência humana, apresentando uma relação direta com a formação de futuros profissionais, ele segue sendo um trabalho relegado à família, considerado pouco relevante e executado predominantemente por mulheres (ARRUZZA; BHATTACHARYA; FRASER, 2019).

De maneira geral, os momentos angustiantes vivenciados pelas mulheres, quando se dedicaram exclusivamente aos filhos, somados às dificuldades enfrentadas no trabalho, em função da maternidade, reforçam a crítica referente à retórica da escolha do fenômeno opt-out (STONE, 2007; VAVRUS, 2007). De acordo com o resultado deste artigo, a decisão de interromper a carreira, em função da maternidade, na maioria dos casos, pode ser mais complexa e conflituosa, se contrapondo aos valores neoliberais que enfatizam a liberdade de escolha e a agência como indicadores da libertação feminina (AKASS, 2012; ORGAD; DE BENEDICTIS, 2015).

A seguir, foi elaborado o quadro 2 para apresentar a síntese dos resultados encontrados. 
Quadro 2 - Síntese dos principais resultados encontrados

\begin{tabular}{|c|c|c|}
\hline Questões de Pesquisa & Categorias & Temas que surgiram nas entrevistas \\
\hline \multirow{16}{*}{$\begin{array}{l}\text { Quais foram os motivos } \\
\text { que levaram mulheres } \\
\text { com carreiras } \\
\text { consolidadas a } \\
\text { aderirem ao } \\
\text { movimento opt-out? }\end{array}$} & \multirow{7}{*}{$\begin{array}{c}\text { Obstáculos do } \\
\text { Mundo do } \\
\text { Trabalho }\end{array}$} & Intensidade do trabalho \\
\hline & & $\begin{array}{l}\text { Ambiente profissional com ritmos e expectativas fixados } \\
\text { pelos homens }\end{array}$ \\
\hline & & Falta de alternativas flexíveis \\
\hline & & Estigma existente nas organizações contra mães \\
\hline & & Insatisfação com o trabalho \\
\hline & & Demissão \\
\hline & & Longo tempo despendido entre casa e trabalho \\
\hline & \multirow{7}{*}{$\begin{array}{l}\text { O Exercício da } \\
\text { Maternidade }\end{array}$} & Desejo de exercer a maternidade em período integral \\
\hline & & $\begin{array}{l}\text { A dedicação exclusiva da mãe gera um diferencial na } \\
\text { formação de valores e desenvolvimento dos filhos }\end{array}$ \\
\hline & & Dificuldade para engravidar \\
\hline & & Dificuldade para passar pela fase do puerpério \\
\hline & & $\begin{array}{l}\text { Interrupção do aleitamento materno no retorno ao } \\
\text { trabalho reunerado }\end{array}$ \\
\hline & & Abdicação de serviços terceirizados de cuidado \\
\hline & & Problemas de saúde dos filhos \\
\hline & \multirow{2}{*}{$\begin{array}{l}\text { A Ausência } \\
\text { Paterna }\end{array}$} & $\begin{array}{l}\text { Expectativas (tradicionais) diferentes sobre os papéis de } \\
\text { homens e mulheres }\end{array}$ \\
\hline & & Intensa rotina de trabalho dos homens \\
\hline \multirow{8}{*}{$\begin{array}{l}\text { Como foi a vivência } \\
\text { dessas mulheres } \\
\text { durante o tempo em } \\
\text { que ficaram em casa? }\end{array}$} & \multirow{8}{*}{$\begin{array}{l}\text { Desafios da } \\
\text { Maternidade } \\
\text { em Período } \\
\text { Integral }\end{array}$} & Sentimento de alívio e libertação \\
\hline & & Crises de Identidade \\
\hline & & Domesticidade privilegiada \\
\hline & & $\begin{array}{l}\text { Tarefas da casa e de cuidado passam a ser de domínio } \\
\text { unicamente feminino na visão dos homens }\end{array}$ \\
\hline & & Desajuste matrimonial \\
\hline & & Perda da autonomia financeira \\
\hline & & Sentimento de improdutividade \\
\hline & & Medo da volta ao trabalho remunerado \\
\hline
\end{tabular}

Fonte: Elaboração das autoras

Vale destacar que grande parte dos temas identificados e analisados reforçam as contribuições de pesquisas anteriores sobre o fenômeno opt-out. Entretanto, dentre os resultados oriundos do campo, constatou-se que quatro temas ainda não foram explorados pela literatura pesquisada: (1) o longo tempo despendido durante o trajeto casa-trabalho; (2) a dificuldade para engravidar; (3) a fase do puerpério; e (4) a interrupção do aleitamento materno. 


\section{CONSIDERAÇÕES FINAIS}

A presente pesquisa buscou compreender as experiências das mulheres que interromperam suas carreiras para se dedicarem em tempo integral aos filhos. Para atingir tal objetivo, duas perguntas de pesquisa foram analisadas: Quais foram os motivos que levaram mulheres com carreiras consolidadas a aderirem ao movimento opt-out? Como foi a vivência dessas mulheres durante o tempo em que ficaram em casa? Para tanto, foram construídas quatro categorias de análise e identificados vinte e quatro temas. Inicialmente, constatou-se que, além do desejo de dedicação à maternidade, outros fatores relacionados às demandas do trabalho e ao baixo envolvimento dos companheiros com as tarefas de cuidados condicionaram, fortemente, a adesão ao fenômeno. Com exceção de uma entrevistada, a decisão de deixar o mercado de trabalho não foi uma simples questão de preferência, como referencia o termo optout: as escolhas das entrevistadas foram conflituosas e decorrentes, principalmente, da impossibilidade de conciliar as exigentes demandas dos ambientes profissional e familiar. $\mathrm{O}$ "tudo ou nada" exigido por um mercado de trabalho cada vez mais competitivo, que inclui jornadas intermináveis, fortes pressões por resultados e pouca receptividade às questões pessoais e familiares de seus funcionários, deixaram as mulheres sem alternativas para equilibrar todas as demandas da sua vida, o que levou-as a interromper suas carreiras.

Além do conflito trabalho-família, as razões relacionadas ao trabalho que levaram as entrevistadas a interromper suas carreiras, incluem: falta de alternativas flexíveis oferecidas pelas organizações; preconceito contra mães no local de trabalho; tempo elevado de deslocamento entre casa e trabalho; e demissão acompanhada de um sabático. No tocante às causas associadas aos filhos, estão: o desejo de exercer unicamente a maternidade; dificuldades vivenciadas pelas entrevistadas antes e durante a maternidade (dificuldade para engravidar, puerpério e interrupção do aleitamento materno); e problemas com a saúde dos filhos. Por fim, os motivos relacionados aos pais compreendem: a naturalização dos papéis tradicionais de gênero e a consequente divisão desigual das atividades de cuidado e domésticas.

Apesar da decisão de interromper a trajetória profissional ter sido difícil para a maioria das mulheres pesquisadas, estar inteiramente disponível para os filhos e sem as pressões do emprego, gerou, em um primeiro momento, uma sensação de alívio e de liberdade. No entanto, com o passar do tempo, a organização da nova vida, centrada no lar e na família, tornou-se angustiante, gerando crises de identidade. Muitas entrevistadas se sentiram perdidas quando se afastaram de suas vidas profissionais, como se subitamente deixassem de ter personalidade própria. Palavras fortes como morte e renascimento foram mencionadas por elas, com o intuito de relacionar os sentimentos de distanciamento do trabalho e a nova fase de dedicação exclusiva aos filhos. Para as entrevistadas, atuar na função de dona de casa nunca esteve em seus planos, o que tornou tal vivência desconfortável. Durante o tempo no lar, um misto de sentimentos tomou conta de suas vidas e, embora reconhecessem o privilégio de poderem estar em casa com os filhos, cuidando e acompanhando seu desenvolvimento, também vivenciavam uma angústia associada à improdutividade e à incerteza quanto ao futuro profissional. Somado a isso, o fato de os companheiros e os filhos se acostumarem com a sua presença em casa, fez com que a subordinação delas à família se ampliasse.

Como já mencionado, dentre os resultados apresentados acima, quatro temas ainda não foram explorados pela literatura pesquisada, configurando-se como uma importante contribuição desta pesquisa para o avanço do conhecimento na área: (1) o longo tempo despendido durante o trajeto casa-trabalho; (2) a dificuldade para engravidar; (3) a fase do puerpério; e (4) a interrupção do aleitamento materno.

Durante a análise, foi interessante notar como, em nenhum momento, as entrevistadas consideraram a possibilidade dos seus companheiros se afastarem de suas carreiras para se dedicarem aos filhos. Longe disso, seus relatos reforçaram a cultura patriarcal dominante que atrela às mulheres as atividades de cuidado e aos homens a responsabilidade pelo provimento 
do lar. Vale ainda destacar, que a responsabilidade por possíveis crises matrimoniais decorrentes do novo modelo de vida "escolhido" pelas mulheres, após a interrupção de carreira, foi assumida por elas.

Também foi possível perceber, a partir das narrativas, a centralidade que o trabalho tem na vida das entrevistadas, revelada, principalmente, pelos sentimentos de improdutividade, medo do futuro e crises de identidade, vivenciados por elas enquanto exerceram unicamente a maternidade; e pela reprodução da linguagem comum às profissionais executivas, como função e gestão, nos assuntos relacionados à esfera privada. Tal fato pode ser associado ao alto senso de identificação que as participantes desta pesquisa possuem com o trabalho remunerado. Tal identificação aponta para a presença de uma ideologia hegemônica e encapsuladora do mundo do trabalho que leva a sociedade, como um todo, a valorizar o trabalho assalariado e a desvalorizar o trabalho de criação de futuros cidadãos, visto como feminizado, sentimentalizado e pouco relevante, realizado por amor em oposição ao dinheiro.

Por fim, um último ponto importante a ser destacado refere-se ao perfil das participantes da presente pesquisa. As quatorze entrevistadas são brancas, casadas e pertencentes à classe social média/alta, o que as relaciona a um locus privilegiado de classe e raça. Elas apenas conseguiram tomar a decisão de interromper as suas carreiras, devido a boa condição financeira de seus companheiros, que assumiram todas as despesas familiares, ou porque conseguiram, ao longo de suas trajetórias profissionais construir uma reserva financeira que as permitiu "escolher" pelo cuidado exclusivo dos filhos, por um determinado período.

Em linha com estudos anteriores (VAVRUS, 2007; STONE, 2007; AKASS, 2012; LEWIS; BENSCHOP; SIMPSON, 2017), os achados desta pesquisa nos levam a pôr em xeque a ênfase dada à questão da livre escolha presente na narrativa que descreve o fenômeno optout. Apesar de as entrevistadas terem feito uma "escolha", os diversos fatores que a condicionaram são indicativos da permanência de barreiras que dificultam a conciliação, para mulheres, das esferas profissional e familiar. Nesse sentido, a narrativa que enfatiza a decisão de interromper a carreira como sinal de agência e libertação feminina, obscurece as desigualdades estruturais e a discriminação de gênero existente na sociedade e, consequentemente, nas organizações. Desta maneira, entendimentos sobre as consequências geradas pelo fenômeno opt-out, como apresentado neste artigo, são importantes para compreender os gaps de gênero persistentes em um mercado de trabalho que hoje, as mulheres tem grande e importante atuação. Em termos gerais, os resultados deste trabalho reforçam a importância de políticas públicas que favoreçam a conciliação das demandas familiares e profissionais; a necessidade de práticas de gestão corporativas que atendam às necessidades familiares e de vida de todos os seus funcionários, além de transformações culturais mais profundas que efetivamente incluam os pais nas tarefas de educação e cuidado dos filhos. Este estudo possui duas limitações principais. A primeira, é que a pesquisa considerou um conjunto bastante homogêneo de mulheres, que contam com um nível socioeconômico privilegiado e experiências de emprego bem sucedidas, o que faz parte apenas da realidade de uma minoria de mulheres brasileiras. A segunda, diz respeito a pesquisa ter sido feita apenas com mulheres de uma mesma região, no caso a região Sudeste brasileira. Um estudo para compreender, em maior profundidade, experiências de mulheres diversas com o fenômeno opt-out, poderia levar em consideração diferentes origens étnicas, sociais e regionais, cujas vivências, oportunidades e estratégias podem diferir.

Em termos de pesquisas futuras, seria interessante compreender as experiências de retorno dessas mulheres para o mercado de trabalho, após o período de dedicação integral aos filhos. Analisar, por exemplo, se elas voltaram para as suas áreas de atuação, ou se elas procuraram se reinventar profissionalmente para viver sobre os seus próprios termos. Por fim, sugere-se também aprofundar o entendimento sobre os temas atrelados ao exercício cotidiano da maternidade, que surgiram nessa pesquisa e que ainda não foram explorados pela literatura 
do fenômeno opt-out, como a dificuldade para engravidar, a fase do puerpério, e a interrupção do aleitamento materno.

\section{REFERÊNCIAS}

AKASS, K. Motherhood and myth-making: Despatches from the frontline of the US mommy wars. Feminist Media Studies, v. 12, n. 1, p. 137-141, 2012.

ARRUZZA, C.; BHATTACHARYA, T.; FRASER, N. Feminismo para os 99\% - UM MANIFESTO. 1. ed. São Paulo: Boitempo, 2019.

BAKER, M. Choices or constraints? Family responsibilities, gender and academic career. Journal of Comparative Family Studies, v. 41, n. 1, p. 1-18, 2010.

BARBOSA, P. Z.; ROCHA-COUTINHO, M. L. Maternidade: novas possibilidades, antigas visões. Redalyc, 2007.

BARDIN, L. Análise de conteúdo. 1. ed. São Paulo: 2016.

BELKIN, L. A Revolução Opt-Out - The New York Times, 2003.

BERNARD, H. R. Research methods in anthropology: qualitative and quantitative approaches. AltaMira P ed. Lanham, MD: 2005.

BIESE, I. Opting Out and In: on womens careers and new lifestyles. first ed. New York: Routledge, 2017.

CUDDY, A. J. C.; FISKE, S. T.; GLICK, P. When professionals become mothers, warmth doesn't cut the ice. Journal of Social Issues, v. 60, n. 4, p. 701-718, 2004.

DESSEN, M. A.; BRAZ, M. P. Rede social de apoio durante transições familiares decorrentes do nascimento de filhos. Psicologia: Teoria e Pesquisa, v. 16, n. 3, p. 221-231, 2000.

ELY, R. J.; STONE, P.; AMMERMAN, C. Rethink What You \&quot; Know \&quot; About High-Achieving Women. Harvard Business Review, 2014.

FILIPPE, M. Licença para Escolher. Revista Exame - Abril, p. 56-58, 27 nov. 2019.

GASCOIGNE, C.; PARRY, E.; BUCHANAN, D. Extreme work, gendered work? How extreme jobs and the discourse of 'personal choice' perpetuate gender inequality. Organization, v. 22, n. 4, p. 457-475, 2015.

GILL, R. Gender and the Media. Malden, USA: Polity Press, 2007.

GOMES, A. G. et al. Maternidade em idade avançada: aspectos teóricos e empíricos. Interação em Psicologia, v. 12, n. 1, p. 99-106, 2008.

GREEN, F. Why has work effort become more intense? Industrial Relations, v. 43, n. 4, p. 709-741, 2004. 
HOCHSCHILD, A. R. The outsourced self. What happens when we pay others to live our lives for us. New York: Picador, 2012.

IBGE - INSTITUTO BRASILEIRO DE GEOGRAFIA E ESTATÍSTICA. Mulheres dedicam mais horas aos afazeres domésticos e cuidado de pessoas, mesmo em situações ocupacionais iguais a dos homens. Rio de janeiro, 2019. Disponível em: https://agenciadenoticias.ibge.gov.br/agencia-sala-de-imprensa/2013-agencia-denoticias/releases/24266-mulheres-dedicam-mais-horas-aos-afazeres-domesticos-e-cuidado-depessoas-mesmo-em-situacoes-ocupacionais-iguais-a-dos-homens

KUPERBERG, A.; STONE, P. The media depiction of women who opt out. Gender and Society, v. 22, n. 4, p. 497-517, 2008.

LEMOS, A. H. C.; CAVAZOTTE, F. DE S. C. N. É possível ter tudo? Carreira, maternidade e extensão da jornada na contemporaneidade. In: CARVALHO NETO, A.; VERSIANI, F. (Eds.). . Mulheres Profissionais: quem é o sexo frágil? first ed. Belo Horizonte, MG: PUC MINAS, 2018. p. 295.

LEMOS, A. H. C.; GOTTLIEB, L. S. N.; COSTA, A. DE S. M. DA. Pressure, Performance and Prestige: Dilemmas for Contemporary Professionals. Organizações \& Sociedade, v. 23, n. 79, p. 539-552, 2016.

LEWIS, P.; BENSCHOP, Y.; SIMPSON, R. Postfeminism, Gender and Organization. Gender, Work and Organization, v. 24, n. 3, p. 213-225, 2017.

LOVEJOY, M.; STONE, P. Opting Back In: The Influence of Time at Home on Professional Women's Career Redirection after Opting Out. Gender, Work and Organization, v. 19, n. 6, p. 631-653, 2012.

MAINIERO, L. A.; SULliVAN, S. E. The Opt-Out Revolt: why people are leaving companies to create Kaleidoscope Careers. 1st. ed. Mountain View, California: DaviesBlack Publishing, 2006a.

MCGRATH, M.; DRISCOLL, M.; GROSS, M. Back in the Game: Returning to Business After a Hiatus. Wharton Center for Leadership and Change, n. June, p. 1-39, 2005.

MCKIE, L.; BIESE, I.; JYRKINEN, M. "The best time is now!": The temporal and spatial dynamics of women opting in to self-employmentGender, Work and Organization, 2013.

MORGADO, A. P. D. V. A Mulher Invisível: sentidos atribuídos a mulher e ao trabalho na gerência intermediária. [s.l.] Fundação Getulio Vargas, 2012.

NEVES, D. R.; NASCIMENTO, R. P. A DIVISÃO ENTRE TRABALHO, FAMÍLIA E ORGANIZAÇÕES PARA CASAIS DE DUPLA JORNADA (TWO-JOB COUPLES): Notas para um Debate sobre o Caso Brasileiro. Revista Economia \& Gestão, v. 17, n. 48, p. 157$173,2018$.

ORGAD, S.; DE BENEDICTIS, S. The 'stay-at-home' mother, postfeminism and neoliberalism: Content analysis of UK news coverage. European Journal of Communication, 
v. 30, n. 4, p. 418-436, 2015.

STONE, P. The Rhetoric and Reality of "Opting Out". Contexts, v. 6, n. 4, p. 14-19, 2007.

STONE, P.; HERNANDEZ, L. A. The all-or-nothing workplace: Flexibility stigma and "opting out" among professional-managerial women. Journal of Social Issues, v. 69, n. 2, p. 235-256, 2013.

STONE, P.; LOVEJOY, M. Fast-track women and the "choice" to stay home. Annals of the American Academy of Political and Social Science, v. 596, n. November, p. 62-83, 2004.

STONE, P.; LOVEJOY, M. Opting Back In: what really happens when mothers go back to work. Oakland, California: University of California Press, 2019.

VAVRUS, M. D. Opting out moms in the news: Selling new traditionalism in the new millennium. Feminist Media Studies, v. 7, n. 1, p. 47-63, 2007. 